\title{
IgE screening in 1701 newborn infants and the development of atopic disease during infancy
}

\author{
S CRONER, N-I M KJELLMAN, B ERIKSSON, AND A ROTH
}

Department of Paediatrics, University Hospital, Linköping, and Pharmacia Diagnostics AB, Uppsala, Sweden

SUMmaRY IgE screening was done using the Phadebas IgE PRIST technique on the cord blood of 1701 newborn infants. Of these $8 \cdot 3 \%$ developed obvious or probable atopic disease, predominantly atopic dermatitis and bronchial asthma, during the first 18 months of life. Of infants with a family history of atopic disease $10.5 \%$ developed such illness; the corresponding figure for infants with an initially high IgE concentration was $70 \%$. Atopic disease developed in $73 \%$ of infants with a high IgE concentration in cord blood and a family history, but in only $3 \%$ of infants with a low IgE and no family history. A high IgE concentration in cord blood was associated with a high IgE and a positive radioallergosorbent test at between ages 18 and 24 months more often than was a low initial IgE level, indicating that in man as in animals there are high and low IgE responders already genetically coded at birth. IgE screening in cord blood is recommended if there is obvious atopy in both parents or if severe atopic disease is present in a sibling or in one parent.

Since the detection of IgE in the mid-1960s overwhelming evidence has been presented concerning the correlation between atopic disease and raised IgE levels. High IgE levels were present before the manifestation of atopic symptoms in studies on selected groups of children including newborn infants. $^{1-4}$ The cumulative incidence of atopic disease in schoolchildren was investigated in relation to an immediate family history of such disease. ${ }^{5}$

The main purpose of the present investigation was to study the predictive value of the total IgE concentration in cord blood with regard to the development of atopic disease and IgE levels during infancy and to the influence of hereditary factors.

\section{Material and methods}

Of 1884 children born at the University Hospital, Linköping during a 13-month period, 1701 (862 boys and 839 girls) were available for IgE determination in cord blood $\left(\operatorname{IgE}_{0}\right)$ and history-taking by questionnaire at age 18 months.

Serum from cord blood was separated and frozen to $-20^{\circ} \mathrm{C}$ within 24 hours. Total IgE was measured with Phadebas IgE PRIST (Pharmacia Diagnostics AB, Uppsala, Sweden). The test was calibrated for a detection limit of $0.9 \mathrm{kU} / 1$. An IgE concentration of $1.3 \mathrm{kU} / 1$ was chosen as the cut-off limit as this was the geometrical mean +2 SD level in our previous study. ${ }^{6}$
Screening for specific IgE antibodies to hen's egg and cows' milk was performed in duplicate with Phadebas RAST (Pharmacia Diagnostics AB, Uppsala, Sweden). To increase the sensitivity of the test, the incubation with the discs was performed with $100 \mu l$ of serum for 18 hours, and the discs were placed in new tubes before gamma counting was done. Two extra dilutions were made of the reference serum to allow for 2 lower standards: 0.13 PRU/ml (Phadebas RAST units) and 0.04 PRU. The total amount of radioactivity bound was $55672( \pm 511)$ counts per minute. Sixty children with an IgE $\geqslant 1.3 \mathrm{kU} / 1$ and 60 with a lower IgE level $(<1 \cdot 3$ $\mathrm{kU} / \mathrm{l})$ taken at random were included in this special study.

The history of possible atopic disease was obtained by a questionnaire filled in by the parents when each child was aged 18 months, covering family history (FH) of atopic disease defined as immediate FH (mother, father, or siblings) or remote FH (grandparents or other relatives), and concerning the child's own symptoms since birth regarding skin, respiratory tract, eyes, nose, and gastrointestinal tract. Answers were read without knowledge of the $\mathrm{IgE}_{0}$ level. The 132 doubtful answers were checked by telephoning the parents.

One hundred and ninety-three infants were examined clinically at 21 (range 18-24) months if atopic disease was suspected from the answers $(n=142)$ or if there were high $\operatorname{IgE}_{0}$ levels $(n=51)$. 
All medical records were scrutinised. To establish a diagnosis a second blood sample for IgE determination $\left(\operatorname{IgE}_{18}\right)$ was taken in 174 of the 193 children. The detection limit of Phadebas IgE PRIST was now $0.5 \mathrm{kU} / 1$. RAST screening was done in 165 of these 174 for specific IgE antibodies to meadow fescue (Festuca elatior), and birch (Betula verrucosa) pollen, animal dander (cat and horse), mites (Dermatophagoides pteronyssinus), mould (Cladosporium), and food allergens (hen's egg, cows' milk, wheat, and soy). The results were expressed in Phadebas RAST classes, 0 indicating no antibodies and 1-4 indicating increasing amounts of specific antibodies.

Obvious atopic disease was diagnosed by the presence of symptoms or signs of atopic dermatitis, bronchial asthma, allergic rhinoconjunctivitis, allergic urticaria, or gastrointestinal allergy.

Probable atopic disease was said to be present if there was a history of specified symptoms or signs of disease not observed at the time of examination, including itching flexural eczema, recurrent wheezing during infections or on other occasions, a constant nasal discharge, or attacks of sneezing and itching eyes without respiratory infection.

Written, informed consent was obtained from the parents, as was approval from the ethics committee. The data were computerised. Statistical methods used were the $\chi^{2}$-test, Fisher's exact test, Student's $t$ test, and variance analysis.

\section{Results}

IgE in cord blood was $\geqslant 1.3 \mathrm{kU} / 1$ in $90(5.3 \%)$ children, $63(7.3 \%)$ boys and $27(3.2 \%)$ girls. The sex difference is statistically significant $(P<0.001)$. The incidence of high $\operatorname{IgE}_{0}$ concentrations did not differ significantly between children with a history of maternal $(14 / 224)$ or paternal (13/165) atopic disease. $\operatorname{IgE}_{0}$ was below detectable levels $(<0.9$ $\mathrm{kU} / \mathrm{l}$ ) in all cases in which the pregnancy had lasted less than 37 weeks $(n=49)$.

No specific IgE-antibodies to cows' milk or hen's egg could be detected in the cord blood of any child; all concentrations were under 0.04 PRU (error of the method about $10 \%$ ).

Obvious or probable atopic disease developed in $142(8.3 \%)$ children, $84(9.7 \%)$ boys and $58(6.9 \%)$ girls (Fig. 1). The sex difference is again statistically significant $(\mathrm{P}<0.05)$. Atopic dermatitis and bronchial asthma were the most common manifestations of atopic disease during the observation period: $5.7 \%$ of the infants had atopic dermatitis, and $1.7 \%$ bronchial asthma. Additional symptoms of uncertain aetiology included repeated reactions to food (390 (22.9\%) infants), napkin rash (674; $39.6 \%$ ), unspecific rashes $(487 ; 28.6 \%)$, itching

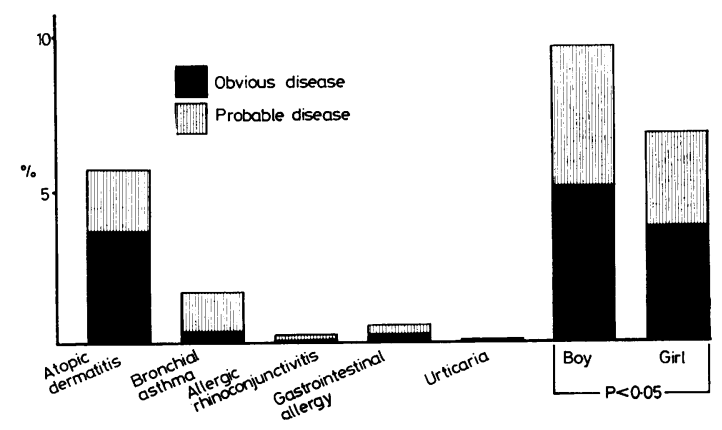

Fig. 1 Cumulative incidence (\%) of obvious and probable atopic disease.

dermatitis $(232 ; 13.6 \%)$, drug-treated colic $(260$; $15.3 \%$ ), drug hypersensitivity $(116 ; 6.8 \%$ ), and rash after vaccination with polio or DTP vaccine (37; $2 \cdot 1 \%$ ).

Of the 142 infants examined clinically at 18 months $122(85.9 \%)$ were considered to have atopic disease on the basis of the answers to the questionnaire.

Most infants with a high $\operatorname{IgE}_{0}$ concentration (63 $(70 \%)$ of 90 ) developed obvious or probable atopic disease during the observation period, whereas the rest $(27(30 \%)$ of 90$)$ did not (Fig. 2). The 6 infants with the highest $\operatorname{IgE}_{0}$ concentrations (10-28 kU/1) developed signs of atopy, but there was otherwise no clear correlation to the incidence of atopic disease during infancy (Table 1). Atopic

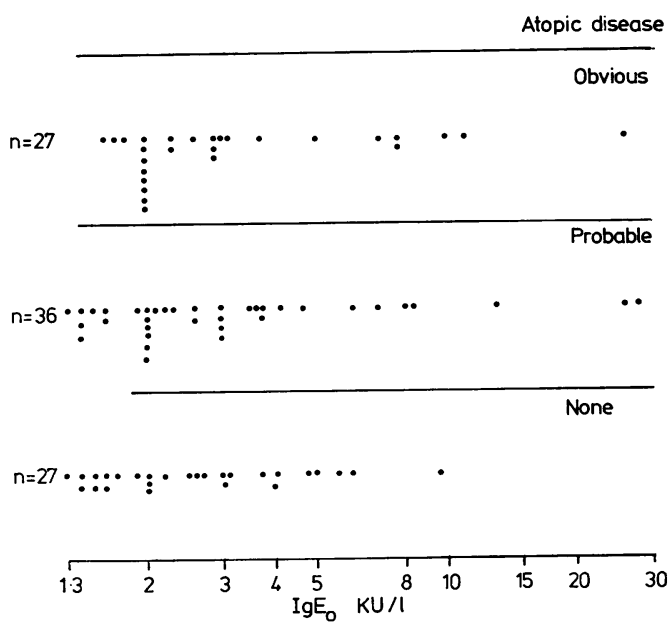

Fig. 2 Clinical diagnosis in infants with raised $I g E_{0}$ concentrations. 
Table 1 Atopic disease in relation to $I g E_{0}$

\begin{tabular}{lllll}
\hline IgE & \multicolumn{4}{l}{ Atopic disease 0-18 months of age } \\
\cline { 2 - 5 } & Obvious & Probable & None & Total \\
\hline$<1 \cdot 3$ & 49 & 30 & 1532 & 1611 \\
$\geq 1.3$ & 27 & 36 & 27 & 90 \\
\hline
\end{tabular}

disease, obvious or probable, was found significantly more often among the infants with high $\operatorname{IgE}_{0}$ level $(\mathrm{P}<0.001)$.

There was close correlation between the IgE concentration at 18 months and the intensity of symptoms: the mean $\operatorname{IgE}_{18}$ level in infants with obvious atopic disease was significantly higher than in those with probable atopic disease and still higher than in apparent healthy infants (Table 2). The $\operatorname{IgE}_{18}$ concentration (Table 3 ) tallied with the IgE $_{0}$ level $(P<0.001)$.

Specific IgE antibodies (Fig. 3) were found in a higher proportion in infants with high $\operatorname{IgE}_{0}$ and obvious $(60 \%)$ or probable $(48.3 \%)$ atopic disease at 18 months than in the other groups. Specific antibodies in radioallergosorbent test (RAST) classes 1-3 were found only to food allergens, most commonly hen's egg and wheat (Table 4). A positive RAST was found in $4(5.1 \%)$ of 79 when $\operatorname{IgE}_{18}$ was below $10 \mathrm{kU} / \mathrm{l}$, in $5(20 \%)$ of 25 when $\operatorname{IgE}_{18}$ was $10-20 \mathrm{kU} / 1$, in $21(52.5 \%)$ of 40 when $\operatorname{IgE}_{18}$ was $20-100 \mathrm{kU} / 1$, and in $18(81.8 \%)$ of 22 when $\operatorname{IgE}_{18}$ exceeded $100 \mathrm{kU} / \mathrm{l}$.

A FH of atopic disease, immediate or remote, was found in $998(58.7 \%)$ infants (Table 5). In $52(3.1 \%)$ of the infants both parents had allergies, and $23.1 \%$ developed atopic disease. Atopic disease occurred in $10.5 \%$ of children with $\mathrm{FH}$ but in $5.3 \%$ if there was no FH $(\mathrm{P}<0.001)$.

Table 2 Atopic disease in relation to $\operatorname{Ig} E_{18}$

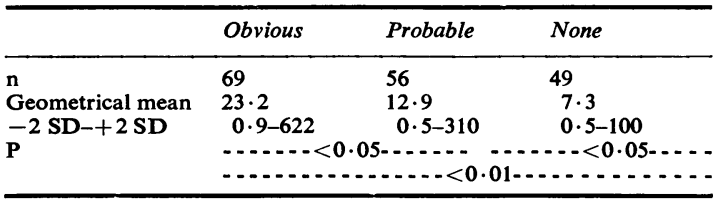

Table $3 \quad I g E_{18}$ in relation to $\operatorname{Ig} E_{0}$

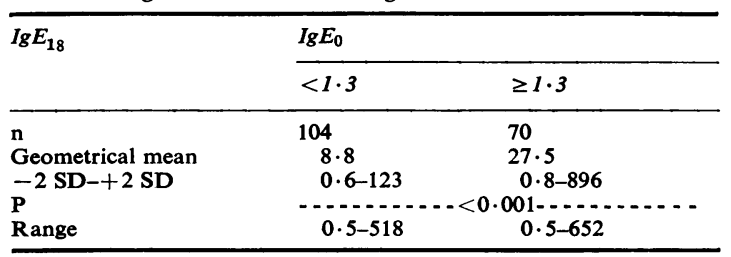

Infants with an immediate FH showed a higher incidence of raised $\operatorname{IgE}_{0}(38(7.2 \%)$ of 528$)$ than infants with no FH $(27(3.8 \%)$ of 703$)(\mathrm{P}<0.01)$. With a remote $\mathbf{F H}$ the incidence was intermediate $(25(5.3 \%)$ of 470$)$.

Seventy-three per cent of infants with a $\mathrm{FH}$ and high $\operatorname{IgE}_{0}$ developed atopy (Fig. 4), but only $3 \%$ with no FH and normal $\operatorname{IgE}_{0}$ did so $(\mathrm{P}<0.001)$. When the $\mathrm{IgE}_{0}$ concentration was high there was no significant difference in the incidence of atopic disease at followup between children with or without a FH. The

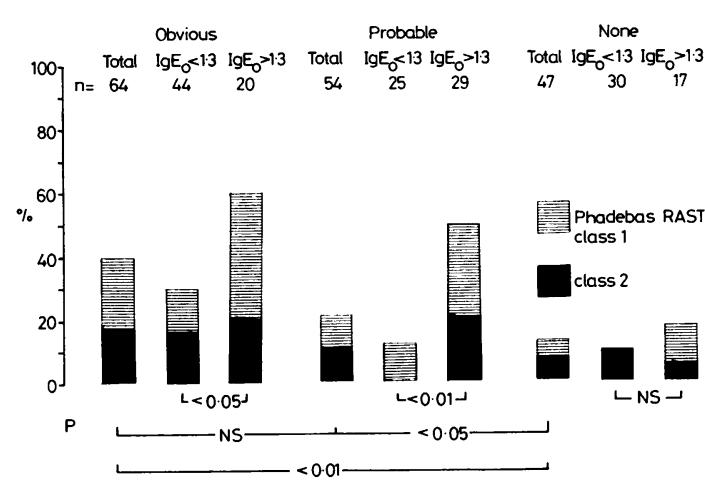

Fig. 3 IgE antibodies ( $R A S T)$ in relation to the clinical diagnosis and $\mathrm{Ig} E_{0}$.

Table 4 Number of infants with positive RAST in relation to the clinical diagnosis at 18 months

\begin{tabular}{|c|c|c|c|c|}
\hline & \multirow[b]{2}{*}{ Obvious } & \multirow[b]{2}{*}{ Probable } & \multicolumn{2}{|c|}{ Atopic disease } \\
\hline & & & None & Total \\
\hline $\mathbf{n}$ & 64 & 54 & 47 & 165 \\
\hline Hen's egg & 16 & 9 & 5 & 30 \\
\hline Wheat & 13 & 11 & 2 & 26 \\
\hline Milk & 6 & 1 & 1 & 8 \\
\hline Soy & 4 & 1 & 1 & 6 \\
\hline \multicolumn{5}{|l|}{ Infants with } \\
\hline positive RAST & 25 & 17 & 6 & 48 \\
\hline
\end{tabular}

Table 5 Atopic disease in relation to family history

\begin{tabular}{llll} 
Atopic disease & \\
\cline { 2 - 2 } & $\%$ & $n$ & $\%$
\end{tabular}

\begin{tabular}{lrrrr}
\hline Immediate & & & & \\
$\quad$ Both parents & 52 & $3 \cdot 1$ & 12 & $23 \cdot 1$ \\
One parent & 389 & 22.9 & 46 & $11 \cdot 8$ \\
$\quad$ Sibling & 87 & $13 \cdot 8$ & 12 & $13 \cdot 8$ \\
$\quad$ Total & 528 & 31.0 & 70 & $13 \cdot 3$ \\
Remote (not immediate) & 470 & 27.6 & 35 & 7.4 \\
Remote + immediate & 325 & $19 \cdot 1$ & 47 & $14 \cdot 5$ \\
Family history & 998 & $58 \cdot 7$ & 105 & 10.5 \\
No family history & 703 & $41 \cdot 3$ & 37 & $5 \cdot 3$ \\
Total & 1701 & $100 \cdot 0$ & 142 & 8.3 \\
\hline
\end{tabular}




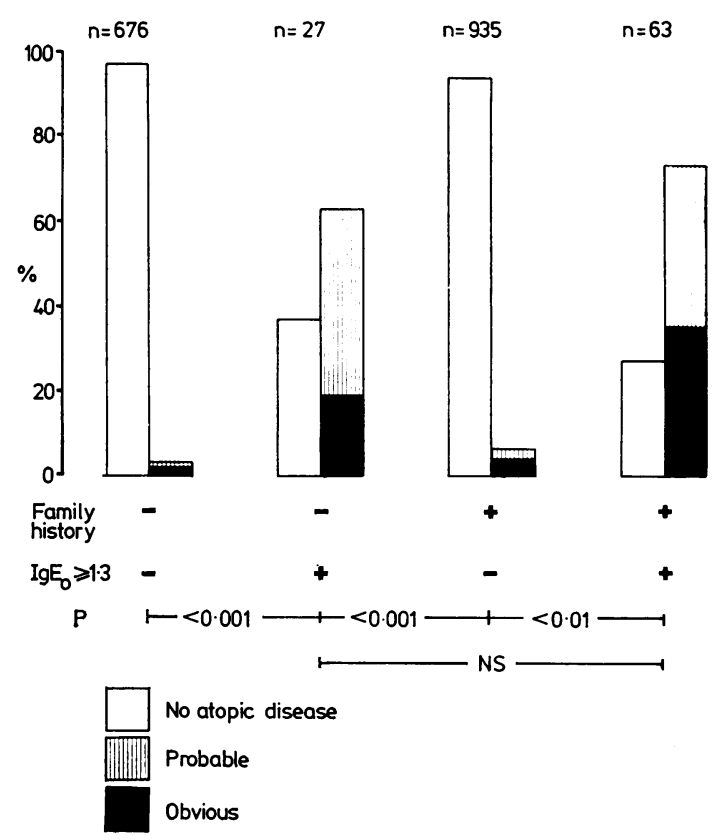

Fig. 4 Clinical diagnosis in relation to $\operatorname{Ig} E_{0}$ and the family history.

incidence of atopic disease did not differ significantly between infants whose mothers had an allergy (22 of 224) and infants whose fathers had an allergy (24 of 166).

\section{Discussion}

The fetus is known to synthesise IgE from the 11th gestational week. ${ }^{7}$ Our IgE findings using the PRIST technique do not suggest that IgE is transmitted across the placental barrier (see also references 8 and 9).

Atopic disease was common in our series: of this random group of consecutively-born children $8 \cdot 3 \%$ developed obvious or possible symptoms or signs of atopy during the first 18 months of life. This conforms with the findings of Halpern et al. who noted allergy in $8 \%$ of a selected series during the first year of life. ${ }^{10}$ Atopic dermatitis and bronchial asthma were, as expected, the predominant features. Atopic disease was more common in boys, which confirms earlier reports. ${ }^{10}$

The incidence of atopic disease could have been overestimated from the answers to the questionnaire alone, but any infant suspected of having atopy was examined at 18-24 months before the diagnosis was established; in most $(86 \%)$ the diagnosis was confirmed. The parents could have misunderstood the questions however, and possibly also mis- interpreted the symptoms; this would result in underestimation of the incidence of atopy. Infantile colic was not taken into consideration when calculating the incidence of atopic disease. Colic may be a sign of allergy. ${ }^{11}$ We did not include symptoms of multifactorial aetiology, which would give a higher incidence of atopic disease.

A family history of atopy was common in our series, especially if remote $\mathbf{F H}$ is included (59\%). Thirty-one per cent of our series had a FH of atopic disease in parents or siblings, which is almost the same as in our earlier study $(30 \%))^{5}$

Most infants with high $\operatorname{IgE}_{0}$ developed atopic disease before age 18 months. A positive FH adds just a little (NS) information to the predictive value of the $\operatorname{IgE}_{0}$. We were thus able to demonstrate the predictive value of a raised IgE level previously found in selected groups of newborn infants, ${ }^{412}$ and to confirm this in an unselected series.

High $\mathrm{IgE}_{0}$ concentrations were also seen in 27 infants showing no signs of atopic disease during the observation period. A recent follow-up when the children were aged $4 \frac{1}{2}$ years suggests that many of these developed symptoms of allergic disease at an older age, thus reducing the number of 'false-positive' results. False-negative $\operatorname{IgE}_{0}$ was common: in fact raised $\operatorname{IgE}_{0}$ was noted in fewer than half of the children who developed atopic disease (63 $(44 \%)$ of 142). Follow-up may show whether infants with raised $I g E_{0}$ develop severer and more enduring signs of allergy than those with low $\mathrm{IgE}_{0}$. Infants with false-negative $\mathrm{IgE}_{0}$ could initially be wrongly classed as having probable atopic disease but later turn out to be free from this.

A high incidence of positive results to RAST was seen among the atopic infants, probably reflecting hyper-reactivity of the immune system but not necessarily clinically relevant at the time of sampling. ${ }^{13}$ The RAST titres became increasingly positive with increasing serum IgE levels. Specific IgE antibodies were found only to common foods. ${ }^{14}$

The existence of high and low IgE responders from genetic reasons has been shown in rats. ${ }^{15}$ In the present study infants with high $\operatorname{IgE}_{0}$ more often developed a positive RAST $_{18}$ and a higher $\operatorname{IgE}_{18}$ concentration than infants with low $\operatorname{IgE}_{0}$, which may imply that in man too there are geneticallypredetermined high IgE responders. ${ }^{16}$ If both parents are allergic it is likely that the children will also have a high IgE concentration. ${ }^{17}$ High IgE responders should be sought out by early screening to allow prophylactic measures, the value of which in selected infants has been shown by Glaser and Johnstone ${ }^{18}$ and others. ${ }^{19-21}$ Further evaluation, including cost-benefit considerations, is required before starting large-scale screening programmes. 
Unlike Michel et al., ${ }^{12}$ we found the child's atopic disease was not influenced more by the mother's allergic disease than by the father's. We found no sign of transplacental transmission of specific antibodies and no specific fetal IgE antibodies; antibodies to egg or milk were not seen in cord blood. IgE at birth is probably 'non-specific'. However, we may not have used the proper antigen in either this or a previous study. ${ }^{5}$ Michel et al..$^{12}$ found IgE antibodies to cows' milk in 3 of 136 newborn infants.

The fetal synthesis of IgE may be stimulated by components in the mother's diet, which possibly cause the 'allergic break-through' suggested by Katz.22 A hypoallergenic maternal diet during pregnancy when both parents suffer from atopic disease might therefore be of prophylactic value for the child. A biparental family history was noted in $3.1 \%$ of our series, which tallies with our previous experience. At 18 months this high genetic risk group was distinguished by the highest incidence $(23.1 \%)$ of atopic disease.

It is too early to advise IgE screening of all newborn infants. A screening procedure must fulfil WHO's recommendations. ${ }^{23}$ The value of prophylactic or other measures ${ }^{24}$ to reduce the risk of atopic disease must be established before a general screening programme is started. At present we recommend IgE screening only when there is obvious atopy in both parents or if severe atopic disease is present in a sibling or one parent.

We thank Mrs Margit Pettersson, Mrs Lena Lindell, Mrs Christina Iveberg, and the midwives in the maternity ward for their assistance, Hans Schröder, Pharmacia AB, for performing the RAST tests, and Mrs Maria Ahlberg and Mrs Kerstin Eriksson for the total IgE determinations.

Riksförbundet mot Allergi, The Swedish Medical Society, and the King Gustav V 80th Anniversary Fund provided financial support.

\section{References}

1 Foucard T. A follow-up study of children with asthmatoid bronchitis. II. Serum IgE and eosinophil counts in relation to clinical course. Acta Paediatr Scand 1974; 63: 129-39.

2 Orgel H A, Hamburger R N, Bazaral M, et al. Development of IgE and allergy in infancy. $J$ Allergy Clin Immunol 1975; 56: 296-307.

3 Kjellman N-I M. Predictive value of high IgE levels in children. Acta Paediatr Scand 1976; 65: 465-71.

4 Dannaeus A, Johansson S G O, Foucard T. Clinical and immunological aspects of food allergy in childhood. II. Development of allergic symptoms and humoral immune response to foods in infants of atopic mothers during the first 24 months of life. Acta Paediatr Scand $\stackrel{\Omega}{\overline{0}}$ 1978; 67: 497-504.

5 Kjellman N-I M. Immunoglobulin E and atopic allergy in $\vec{F}$ childhood. Thesis No 36, Linköping University, 1976: 20.

6 Kjellman N-I M, Johansson S G O, Roth A. Serum IgE 0 levels in healthy children quantified by a sandwich technique (PRIST). Clin Allergy 1976; 6: 51-9.

7 Miller D L, Hirvonen T, Gitlin D. Synthesis of IgE by the human conceptus.J Allergy Clin Immunol 1973; 52: 182-8. Q

8 Johansson S G O. Serum IgND levels in healthy children and adults. Int Arch Allergy 1968; 34: 1-8.

- Bazaral M, Orgel H A, Hamburger R N. IgE levels in $\vec{\circ}$ normal infants and mothers and an inheritance hypothesis. J Immunol 1971; 107: 794-801.

10 Halpern S R, Sellars W A, Johnson R B, Anderson D W, . Saperstein S, Reisch J S. Development of childhood ญ allergy in infants fed breast, soy, or cow milk. $J$ Allergy Clin Immunol 1973; 51 : 139-151.

11 Jakobsson I, Lindberg T. Cows' milk as a cause of infantile colic in breast-fed infants. Lancet 1978; ii : 437-9. ov

12 Michel F B, Bousquet J, Greillier P, Robinet-Levy M, W Coulomb Y. Comparison of cord blood immuno- $\rightarrow$ globulin $\mathrm{E}$ concentrations and maternal allergy for the prediction of atopic diseases in infancy. $J$ Allergy Clin Immunol 1980; 65: 422-30.

13 May C D, Remigio L, Feldman J, Bock S A, Carr R I. A study of serum antibodies to isolated milk proteins and ovalbumin in infants and children. Clin Allergy 1977; 7: $\vec{\omega}$ 583-95.

14 Foucard T. A follow-up study of children with asthmatoid ! bronchitis. I. Skın test reactions and IgE antibodies to common allergens. Acta Paediatr Scand 1973; 62: 633-44. ㅇ

15 Levine B B, Vaz N M. Effect of combinations of inbred strain antigen and antigen dose on immune responsive- $\bar{D}$ ness and reagin production in the mouse. Int Arch Allergy Appl Immunol 1970; 39: 156-71.

16 Marsh D G. HLA and allergy. In: Steffen C, Ludwig H, eds. Clinical immunology and allergology. Developments $\bar{O}$ in Immunology. Vol. 14. Amsterdam: Elsevier, 1981: 157-66.

17 Gerrard J W, Horne S, Vickers P, et al. Serum IgE levels in parents and children. J Pediatr 1974; 85: 660-3.

18 Glaser J, Johnstone D E. Prophylaxis of allergic disease in the newborn. JAMA 1953; 153: 620-2.

19 Saarinen U M, Backman A, Kajosaari M, Siimes M A. ' Prolonged breast-feeding as prophylaxis for atopic 3 disease. Lancet 1979; ii: 163-6.

20 Matthew D J, Normal A P, Taylor B, Turner M W, O Soothill J F. Prevention of eczema. Lancet 1977; i: 321-4.

21 Hamburger $R$ N. Allergies in infants-perhaps they can $ᄋ$ be prevented. Consultant 1979; 19: 23-9.

22 Katz D H. New concepts concerning the clinical control $\frac{D}{O}$ of IgE synthesis. Clin Allergy 1979; 9: 609-24.

23 Wilson J M G, Jungner G. The principles and practice of $\mathrm{N}$ screening for disease. Public Health Papers No 34.

Geneva: WHO, 1968: 26-7.
De Weck A L. Suppression of IgE antibodies. In: Steffen C, Ludwig $\mathrm{H}$, eds. Clinical immunology and $\omega$ allergology. Developments in Immunology. Vol. 14. O Amsterdam: Elsevier, 1981 : 381-8.

Correspondence to Dr Stefan Croner, Department of $\stackrel{\oplus}{\mathscr{D}}$ Paediatrics, University Hospital, S-581 85 Linköping, Sweden.

Received 10 September 1981 